\title{
Pemanfaatan Media Pembelajaran Autograph Menggunakan Pendekatan Problem Solving Untuk Meningkatkan Kemampuan Metakognisi Siswa SMA
}

\section{Utilization of Autograph Learning Media Using Problem Solving Approach to Improve Metacognition Ability of High School Students}

Fitrah Sari Wahyuni Harahap

\author{
Universitas Potensi Utama, Jalan K.L Yos Sudarso KM 6,5 No. 3-A \\ Tanjung Mulia Medan,20241 \\ Email :fitrah18.upu@gmail.com
}

\begin{abstract}
Abstrak
Software Autograph merupakan program khusus yang digunakan dalam pembelajaran matematika. Autograph memiliki kemampuan membuat grafik 2D dan 3D untuk materi tranformasi, kerucut bagian, vektor, kemiringan, dan turunan. Dengan menggunakan software ini, pengguna dapat mengamati bagaimana fungsi, grafik, persamaan, dan perhitungan. Kegiatan pengabdian masyarakat yang dilaksanakan di SMA Swasta Al Fattah khususnya untuk kelas XI diharapkan siswa dapat memahami konsep aplikasi integral yaitu volume benda putar dan respon siswa terhadap pembelajaran matematika melalui media pembelajaran autograph pada materi volume benda putar. Dalam kegiatan pengabdian masyarakat ini diharapkan siswa kelas IX dapat menemukan pemecahan masalah (problem solving) aplikasi integral untuk volume benda putar. Software autograph digunakan untuk mempermudah siswa memahami konsep volume benda putar melalui gambar dua dimensi dan tiga dimensi dengan kemampuan metakognisinya.
\end{abstract}

Kata kunci: Autograph, pemecahan masalah, metakognisi

\begin{abstract}
Autograph Software is a special program used in learning mathematics. Autograph has the ability to make $2 D$ and $3 D$ graphics for material transformation, cone sections, vectors, slope, and derivatives. By using this software, users can observe how functions, graphs, equations, and calculations. Community service activities carried out at Al Fattah Private High School, especially for class XI, are expected students to understand the concept of integral applications, namely the volume of rotating objects and students' responses to mathematics learning through autograph learning media on the material of rotating objects. In this community service activity, it is hoped that class IX students can find an integral application problem solving for the volume of rotating objects. Autograph software is used to make it easier for students to understand the concept of the volume of a rotating object through two-dimensional and three-dimensional images with their metachogical abilities.
\end{abstract}

Key words: autograph, problem solving, metacognition

\section{PENDAHULUAN}

Pendidikan adalah aspek yang sangat berharga untuk meningkatkan sumber daya manusia. Peningkatan sumber daya manusia bukan hanya dari segi kuantitas semata namun sumber daya manusia harus memiliki kualitas yang baik. Kualitas sumber daya manusia harus ada keseimbagan antara kemampuan kognitif dan softskill. Oleh 
karena itu aspek pendidikan harus mengalami perkembangan yang sangat pesat baik dari segi teknologi maupun kualitasnya (Ramadhani, 2017). Sumber daya manusia harus memiliki kemampuan kognitif dan kemampuan metakognisi yang diselaraskan dengan kemajuan teknologi. Salah satu cara untuk menghasilkan sumber daya manusia yang memiliki kemampuan kognitif dan metakognisi yang baik dan mengacu pada kemajuan teknologi, maka peserta didik harus dibiasakan dengan pembelajaran yang berorientasi dengan pendekatan berbasis masalah dengan memanfaatkan teknologi tepat guna. Banyak teknologi yang berkembang pesat di dunia pendidikan. Salah satu diantaranya adalah penerapan Autograph.

Penerapan Autograph yang digunakan pada pembelajaran khususnya pembelajaran matematika diharapkan bisa meningkat kemampuan metakognisi peserta didik. Pembelajaran yang dilakukan dengan berbantuan Autograph membuat kegiatan pembelajaran menjadi menarik dan bermakna. Pembelajaran yang bermakna bisa terwujud dengan adanya pengembangan lembar kerja berorientasi pendekatan dengan penerapan Autograph yang akan melatih siswa untuk mengembangkan kemampuan metakognisinya dengan harapan kemampuan metakognisi siswa akan meningkat. Dengan meningkatnya kemampuan metakognisi siswa secara tidak langsung menyumbang kepada peningkatan kemampuan pemecahan masalah matematika yang pada akhirnya akan menyumbang pada kualitas sumber daya manusia. Lembaga Penelitian dan Pengabdian Masyarakat Universitas Potensi Utama bertanggung jawab mengembangkan dan menyebarluaskan ilmu pengetahuan dan teknologi yaitu dengan mengadakan workshop pengembangan lembar kerja siswa berorientasi pendekatan berbasis penerapan Autograph yang diharapkan mampu untuk meningkatkan kemampuan metakognisi siswa kelas XI SMA Swasta Al Fattah.
Pengembangan lembar kerja siswa berorientasi pendekatan berbasis penerapan Autograph untuk meningkatkan kemampuan metakognisi siswa kelas XI SMA Swasta Al Fattah ini bertujuan agar siswa mampu menggunakan teknologi yang ada dan mengaplikasikanya dalam pembelajaran matematika. Kegiatan ini meliputi pengenalan siswa terhadap media pembelajaran penerapan Autograph, sebagai media pembantu pada pengembangan lembar kerja siswa untuk meningkatkan kemampuan metakognisi siswa yang berorientasi pendekatan berbasis masalah.

Semoga dengan adanya workshop pengembangan lembar kerja siswa berorientasi pendekatan berbasis penerapan Autograph untuk meningkatkan kemampuan metakognisi siswa kelas XI SMA Swasta Al Fattah ini siswa mendapat wawasan serta informasi tentang bagaimana memanfaatkan media pembelajaran yang menarik berbasis teknologi khususnya penerapan Autograph untuk meningkatkan kemampuan metakognisi siswa.

\section{SOLUSI/TEKNOLOGI}

\section{A. Penggunaan Software Autograph \\ 1. Pengertian Autograph}

Autograph merupakan program khusus yang digunakan dalam pembelajaran matematika. Software Autograph memiliki kemampuan membuat grafik $2 \mathrm{D}$ dan 3D untuk materi tranformasi, kerucut bagian, vektor, kemiringan, dan turunan. Dengan menggunakan software ini, pengguna dapat mengamati bagaimana fungsi, grafik, persamaan, dan perhitungan.

\section{Kelebihan menggunakan software Autograph dalam pembelajaran matematika.}

Penerapan Autograph merupakan kontribusi yang menggunakan teknologi untuk mengajar matematika. Model (Autograph software) ini menyoroti kontribusi peralatan digital dan sumber daya yang bermanfaat untuk: 
a. Mempengaruhi proses kerja dan meningkatkan produksi, khususnya dengan meningkatkan kecepatan dan efisiensi proses, dan meningkatkan akurasi dan penyajian hasil, dengan demikian berkontribusi terhadap kecepatan dan produktivitas pelajaran.

b. Memungkinkan siswa untuk memvisualisasikan dan lebih memahami matematika dalam kehidupan nyata

c. Mengatasi kesulitan siswa dan konstruksi gambar, termasuk melewati masalah yang dihadapi oleh siswa ketika menulis dan menggambar dengan tangan dan memfasilitasi koreksi kesalahan, sehingga meningkatkan rasa kemampuan siswa dalam pekerjaan mereka;

d. Pengajaran dengan mengintegrasikan Autograph di sekolah dapat meningkatkan efektivitas dan kualitas mengajar

e. Meningkatkan variasi dan daya penarik aktivitas di kelas, khususnya variasi format pembelajaran dan merubah suasana kelas dengan memperkenalkan unsur bermain, menyenangkan, mengembirakan, dan mempermudah tugas yang sulit.

f. Mengembangkan kebebasan siswa dan pertukaran kelompok teman sebaya, khususnya menyediakan kesempatan bagi siswa untuk latihan mandiri lebih banyak dan bertanggung jawab, berbagi keahlian dan saling mendukung.

g. membantu guru dalam membuat siswa lebih memperhatikan papan tulis interaktif dan bertindak sebagai media interaksi antara siswa atau antara guru dan para siswa.

h. Menguatkan konsep (Aman, Karnasih, \& Dewi, 2018; Ghozi \& Hilmansyah, 2018; Tarmizi, Yunus, Ayub, \& Bakar, 2009).

3. Kekurangan dari software Autograph. Adapun kekurangan dari software ini dalah sebagai berikut :
1. Autograph software ini tidak bisa menyajikan cara untuk menyelesaikan masalah yang diberikan, software ini hanya memberikan hasil.

2. Tidak ada evaluasi bagi siswa karena sifatnya hanya sebagai latihan bagi siswa.

3. Tidak bisa menyelesaikan masalah secara analitis.

\section{Contoh Penggunaan Autograph Pada Materi Matematika \\ Tampilan awal Autograph}

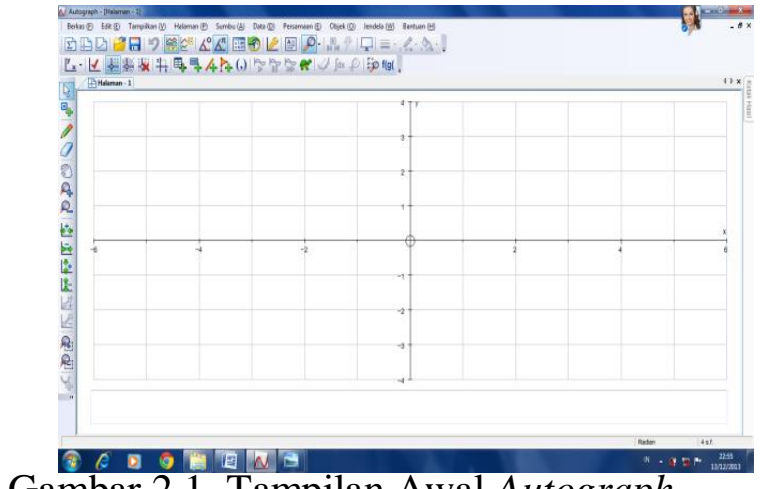

Gambar 2.1. Tampilan Awal Autograph

\section{B. Metode Problem Solving}

Metode pembelajaran Problem

Solving (Ramadhani, 2018) adalah penerapan pembelajaran yang melatih siswa untuk melibatkan kemampuan berpikir memecahkan masalah yang secara praktis dihadapinya. Langkah-langkah pembelajaran metode Problem Solving berbantuan Autograph terdiri dari (1) tahap persiapan, (2) tahap mengerti masalah, (3) tahap merancang rencana, (4) tahap melaksanakan rencana, (5) melihat kembali, (6) penampilan hasil.

Metode pembelajaran Problem Solving berbantuan Autograph untuk meningkatkan kemampuan komunikasi matematis dan kreativitas siswa pada materi aplikasi integral materi volume benda putar dilaksanakan melalui langkahlangkah:

1. Tahap persiapan, disini guru menarik perhatian dengan berdoa yang bertujuan mengajak siswa mempersiapkan secara moril atau 
kejiwaan dengan bimbingan dan lindungan sang pencipta.

2. Tahap mengerti masalah, guru menyampaikan permasalahan, yang sedang kita hadapi dengan memberikan suatu pertanyaan dalam bentuk soal cerita pada lembar soal yang menyangkut masalah nyata yang berhubungan dengan materi yang sedang kita pelajari, dimana pada pembelajaran ini yaitu volume benda putar sebagai aplikasi dari materi integral.

3. Tahap merancang rencana, siswa mulai menyusun langkah-langkah apa yang akan digunakan dalam menyelesaikan soal berbantuan Autograph namun pada final penyelesaian siswa juga diharapkan membuat langkah-langkah penyelesaian secara manual. Disini fungsi bantuan Autograph sebagai evaluasi atau sebagai panduan untuk mengembangkan kreativitas siswa dalam tahap penyelesaian sehingga siswa merasa yakin dengan yang mereka cari secara manual, selain itu juga mempercepat waktu penyelesaian soal. Pada saat siswa membandingkan hasil secara bekerja sama dengan teman kelompoknya disini tercipta suatu komunikasi dan menghasilkan ide-ide matematik dari setiap siswa sehingga suasana pembelajaran menjadi asyik dan siswa tidak akan merasa jenuh dan bosan. Di samping itu guru memberikan arahan tentang materi yang berhubungan dengan soal.

4. Tahap melaksanakan rencana, siswa menyelesaikan masalah /soal yang dihadapi dengan bantuan Autograph yang telah dipersiapkan, guru membagi menjadi beberapa kelompok agar mereka saling berbagi informasi.

5. Melihat kembali, guru mengulas kembali soal yang telah dikerjakan agar siswa lebih mengerti.

\author{
6. Penampilan hasil, siswa \\ menampilkan hasil diskusi yang \\ telah dilakukan.
}

\section{KEMAMPUAN METAKOGNISI}

Metakognisi didefinisikan oleh beberapa ahli sebagai berpikir tentang berpikir, beberapa ahli lain mendefinisikan mengetahui tentang mengetahui. Kemampuan refleksi diri dari suatu proses berpikir atau proses kognitif yang berlangsung pada diri individu dan yang berperan penting dalam kesadaran manusia, itu merupakan suatu petunjuk bahwa metakognisi diikut sertakan pada pemikiran seseorang. Pengertian metakognisi hampir sama dengan pengertian perefleksian terhadap apa yang dipikirkan oleh individu (Alzahrani, 2017). Secara konseptual metakognisi diartikan sebagai suatu pengetahuan seseorang terhadap proses berpikirnya sendiri kemampuan memantau dan mengarahkan proses dan hasil berpikirnya sendiri serta mengevaluasi proses berpikir dan hasil berpikirnya sendiri. Selanjutnya dikatakan bahwa kemampuan metakognisi diyakini sebagai kemampuan tingkat tinggi yang diperlukan untuk manajemen pengetahuan dimana peserta didik dituntut untuk mengatur tujuan belajarnya sendiri dan menentukan strategi belajar sesuai untuk mencapai tujuan tersebut (Fauzi \& Sa'diyah, 2019).

Metakognisi siswa sangat perlu ditingkatkan karena metakognisi merupakan sesuatu kekuatan dari dalam diri siswa tentang suatu proses menyadari kemampuan dan mengatur berpikir siswa dalam memecahkan masalah. Metakognisi pada hakekatnya memberikan penekanan pada kesadaran berpikir tentang proses berpikirnya sendiri. Metakognisi sebagai kemampuan proses seseorang berpikir dalam rangka membangun strategi untuk memecahkan masalah. Konsep dari metakognisi adalah ide dari berpikir tentang pikiran pada diri sendiri. Adapun yang termasuk dalam konsep metakognisi adalah kesadaran tentang: 1) apa yang diketahui sesorang,(kesadaran dan pemahaman yang 
mendalam mengenai proses dan produk yang dimiliki seseorang. (2) apa yang dapat dilakukan oleh seseorang tentang kemampuan kognitif diri sendiri (kemampuan seseorang untuk memonitor atau meregulasi aktiviyas kognisinya selama pemecahan masalah (Ariffin Abu Bakar \& Ismail, 2020). Pentingnya metakognisi diperkenalkan dalam dunia pendidikan oleh karena metakognisi sebagai suatu bentuk kemampuan kognisi, atau kemampuan proses berpikir dua tingkat atau lebih yang melibatkan pengendalian terhadap aktivitas kognitif, Flavell mendefinisikan metakognisi, Metacognition as the ability to understand and monitor one's own thoughts and the assumption and implication of one's activities. Metakognisi sebagai kemampuan untuk memahami berpikir sendiri dan dugaan serta implikasi kegiatan seseorang. Berdasarkan beberapa pendapat di atas maka dapat ditekankan bahwa metakognisi adalah suatu kemampuan untuk memahami kegiatan berpikir, sehingga proses metakognisi tiap-tiap orang akan berbeda menurut kemampuannya, dan sangat perlu ditingkatkan dalam pembelajaran dikelas khususnya pembelajaran matematika (Chairani, 2015) .

Kemampuan metakognisi sangat penting pada pemecahan masalah. Oleh karena itu perlu dikembangkan ataupun ditingkatkan. Menurut Larkin (Larkin, Watts, \& Clifton, 2006) bahwa metakognisi berkembang pada diri individu seiring usia dan dipengaruhi juga oleh latihan. Interaksi satu sama lain dapat memberikan stimulus yang diperlukan oleh individu untuk menjadi lebih menyadari proses kognitif mereka. Oleh karena itu agar metakognisi individu atau peserta didik dapat berkembang dengan baik atau meningkat perlu dilakukan latihan yang memberikan stimulus pada saat pembelajaran di kelas. Stimulus yang diberikan agar lebih maksimal maka stimulus tersebut harus dirancang sedemikian rupa. Adapun stimulus tersebut dapat berupa strategi pembelajaran, pendekatan pembelajaran atau model pembelajaran maupun bahan ajar yang digunakan dan dikembangkan sesuai materi yang diajarkan (Seraphin, Philippoff, Kaupp, \& Vallin, 2012). Lembar aktivitas siswa yang dikembangkan serta pendekatan pembelajaran yang sesuai dengan materi serta karakter peserta didik merupakan solusi untuk memberikan stimulus pada peserta didik agar menunjang pengembangan metakognisi atau meningkatkan metakognisi peserta didik pada saat pemecahan masalah matematika.

\section{HASIL DAN DISKUSI}

\section{Hasil Workshop}

Berdasarkan wawancara, tanya jawab dan pengamatan langsung selama kegiatan berlangsung, kegiatan pengabdian pada masyarakat ini memberikan hasil sebagai berikut:

a. Meningkatnya pengetahuan siswa SMA tentang media pembelajaran.

b. Meningkatnya pengetahuan dan pemahaman siswa SMA dalam menentukan volume benda putar sebagai aplikasi materi integral dengan menggunakan Autograph.

c. Meningkatnya kemampuan matematika siswa.

d. Meningkatnya keterampilan siswa SMA dalam menggunakan software Autograph sebagai media pembelajaran Matematika.

\section{Faktor Pendukung dan Faktor \\ Penghambat}

Selama persiapan dan saat kegiatan berlangsung terdapat beberapa hal yang menjadi faktor pendukung terlaksananya kegiatan pengabdian pada masyarakat ini yaitu besarnya minat, semangat dan keingintahuan peserta dari menjelang kegiatan, selama kegiatan dan setelah kegiatan, seluruh siswa kelas XI SMA Swasta Al Fattah hadir dan datang tepat waktu, sambutan perwakilan sekolah yang hangat dan ramah, penyediaan ruangan yang memadai seperti ruangan kelas, fasilitas komputer, LCD Proyektor dan laboratorium komputer sehingga kegiatan berlangsung dengan lancar, maksimal dan efektif. 
Sedangkan faktor penghambatnya adalah keterbatasan waktu pelatihan dan keterbatasan tim pemateri yang hanya 2 orang sementara peserta sebanyak 23 orang, sehingga ketika banyak yang mengalami kendala saat mengoperasikan langkahlangkah Autograph tim berbagi tugas untuk melayani peserta.

\section{KESIMPULAN}

Dari kegiatan pengabdian pada masyarakat ini dapat disimpulkan bahwa:

1. Pengetahuan siswa tentang media pembelajaran bertambah.

2. Pemahaman siswa SMA dalam menentukan volume benda putar sebagai aplikasi konsep integral meningkat.

3. Kemampuan matematika siswa meningkat.

4. Keterampilan siswa SMA dalam memanfaatkan teknologi dalam pembelajaran meningkat.

\section{UCAPAN TERIMA KASIH}

Dalam kesempatan ini, kami mengucapkan terima kasih yang sebesarbesarnya kepada :

1. Ketua Lembaga Pengabadian Pada Masyarakat Universitas Potensi Utama yang telah memberikan kemudahan dalam pelaksanan pengabdian.

2. Dekan FTIK Universitas Potensi Utama yang telah memberikan fasilitas dalam kegiatan pengabdian ini

3. Ketua dan Sekretaris Program Studi Teknik Informatika yang telah memberikan dukungan dan bimbingan dalam pelaksanaan kegiatan pengabdian ini.

4. Staf dosen dan staf TU Program Studi Teknik Informatika yang telah membantu kelancaran pelaksanaan kegiatan pengabdian ini.

5. Koordinator, Kepala Sekolah, Wakil Kepala Sekolah, Staf Pegawai, guruguru, dan para siswa SMA Swasta
Al Fattah Hamparan Perak yang telah turut berpartisipasi aktif dalam pelaksanaan kegiatan pengabdian ini.

Akhir kata semoga kegiatan pengabdian kepada masyarakat ini dapat bermanfaat bagi peningkatan kualitas pendidikan.

\section{PUSTAKA}

Alzahrani, K. S. (2017). Metacognition and Its Role in Mathematics Learning: an Exploration of the Perceptions of a Teacher and Students in a Secondary School. International Electronic Journal of Mathematics Education, 12(3), 521-537.

Aman, D., Karnasih, I., \& Dewi, I. (2018). The Effect of Problem Based Learning Assisted Autograph on The Improvement of Mathematical Representation. IOSR Journal of Research \& Method in Education (IOSR-JRME), 8(3), 55-60. https://doi.org/10.9790/73880803035560

Ariffin Abu Bakar, M., \& Ismail, N. (2020). Metacognitive Learning Strategies in Mathematics Classroom Intervention: A Review of Implementation and Operational Design Aspect. 15(1), 555. https://doi.org/10.29333/iejme/5937

Chairani, Z. (2015). Perilaku Metakognisi Siswa dalam Pemecahan Masalah Matematika. Jurnal Pendidikan Matematika, 1(3).

Fauzi, A., \& Sa'diyah, W. (2019). Students' metacognitive skills from the viewpoint of answering biological questions: Is it already good? Jurnal Pendidikan IPA Indonesia, $\quad 8(3), \quad 317-327$. https://doi.org/10.15294/jpii.v8i3.1945 7

Ghozi, S., \& Hilmansyah, H. (2018). Visualisasi Geometris Aplikasi Integral: Studi Penggunaan Software Autograph Dalam Pembelajaran Matematika Teknik. JNPM (Jurnal Nasional Pendidikan Matematika), 
2(1),

73. https://doi.org/10.33603/jnpm.v2i1.896

Larkin, M., Watts, S., \& Clifton, E. (2006). Giving voice and making sense in interpretative phenomenological analysis. Qualitative Research in Psychology, Vol. 3, pp. 102-120. https://doi.org/10.1191/1478088706qp0 $62 \mathrm{oa}$

Ramadhani, R. (2017). Peningkatan Kemampuan Pemahaman Konsep dan Kemampuan Pemecahan Masalah Matematika Siswa SMA Melalui Guided Discovery Learning Berbantuan Autograph. Jurnal Penelitian Dan Pembelajaran Matematika, $\quad$ 10(2), 72-81. https://doi.org/10.30870/jppm.v10i2.20 32

Ramadhani, R. (2018). The enhancement of mathematical problem solving ability and self-confidence of students through problem based learning. Jurnal Riset Pendidikan Matematika, 5(1), $127-$ 134.

https://doi.org/10.21831/jrpm.v5i1.132 69

Seraphin, K. D., Philippoff, J., Kaupp, L., \& Vallin, L. M. (2012). Metacognition as means to increase the effectiveness of inquiry-based science education. Science Education International, 23(4), 366-382. Retrieved from http://www.icaseonline.net/sei/decemb er2012/p5.pdf

Tarmizi, R. A., Yunus, A. S. M., Ayub, A. F. M., \& Bakar, K. A. (2009). Integration of Autograph Technology for Learning Algebra. European Journal of Social Sciences, 9(1), 129146. 